\title{
Increased recombination frequencies resulting from directional selection for geotaxis in Drosophila
}

\author{
ABRAHAM B. KOROL* \& KONSTANTIN G. ILIADI $\dagger$ \\ Institute of Evolution, University of Haifa, Mount Carmel, Haifa 31905, Israe/ and $\uparrow$ Institute of Zoology of the Academy \\ of Sciences, Kishinev 277028, Moldova
}

\begin{abstract}
Several classes of models have been suggested to explain how natural selection can favour non-zero recombination. Directional and fluctuating selection, abiotic and biotic, and selection against harmful mutations seem to be the most plausible factors, but little has been done to test the problem experimentally. Here we show that long-term selection for positive or negative geotaxis in Drosophila melanogaster results in a dramatic increase in recombination rates in different genomic regions. The total increment in recombination for the genome portion considered is $78 \mathrm{cM}$ for $\mathrm{geo}^{+}$and $66 \mathrm{cM}$ for $\mathrm{geo}^{-}$. Selection for negative geotaxis did not result in recombination changes in chromosome 2 whereas selection in the opposite direction caused nearly a four-fold increase in the $b$-cn segment and a significant, albeit not as high, increase in the adjacent regions, $a l-b$ and $c n-v g$. In chromosomes $\mathrm{X}$ and 3 , a significant increase in recombination was found in both selected lines. In total, the increment in exchange frequency in chromosome $\mathrm{X}(y-c v-c t-v-c a r)$ was from 72.6 per cent (the control level) to 124.7 and 110.3 per cent geo $^{-}$and $\mathrm{geo}^{+}$, respectively, whereas for the studied portion of chromosome 3 ( $r u-h-c u-s r-e)$ we obtained, correspondingly, 60.8, 76.4 and 73.8 per cent. Thus, in general, selection for geotaxis resulted in increased recombination frequencies regardless of the direction of selection. These results, taken together with other data, allow one to conclude that selection for fitness traits (e.g. for changed levels of quantitative traits, behavioural peculiarities or adaptation to adverse environmental conditions) may be a powerful factor causing rather rapid changes in the recombination system.
\end{abstract}

Keywords: crossing-over, Drosophila, geotaxis, recombination evolution, two-way selection.

\section{Introduction}

Understanding the forces maintaining sex and recombination is one of the most difficult problems in evolutionary theory (Michod \& Levin, 1988). Many models have been proposed for its solution based on hypotheses of combinatorial functions of recombination, i.e. connected with genotypic adaptation to variable environments, both biotic (Hamilton, 1980; Bell \& Maynard Smith, 1987; Korol et al., 1990) and abiotic (Charlesworth, 1976; Maynard Smith, 1980, 1988) and selection against harmful mutations (Felsenstein \& Yokoyama, 1976; Kondrashov, 1988; Charlesworth, 1990). Assuming neutrality of rec-modifiers, it is clear that they can be subjected to only indirect selection which is possible under non-zero linkage dis-

*Correspondence. equilibrium $(D \neq 0)$ between the fitness loci. The latter may result from finite population size or epistasis. In particular, the condition $D \neq 0$ arises under stabilizing selection with a moving optimum (Maynard Smith, 1988). But could these conclusions be tested in nature or in controlled conditions?

Experiments on direct selection for altered recombination frequency $(r f)$ can be viewed as strong evidence for genetic polymorphism at rec-loci (Allard, 1963; Chinnici, 1971; Landner, 1971; Kidwell, 1972; Shaw, 1972; Dewees, 1975; Turner, 1979; Charlesworth \& Charlesworth, 1985). Thus, the key question is whether selection for fitness traits can affect this variation and produce directed changes in $r f$. Despite the keen interest in the problem displayed by theoreticians, it has been poorly studied experimentally and what little evidence has accumulated so far, is almost uncited by them. For example, in two recent books on 
the evolution of sex and recombination (Stearns, 1987; Michod \& Levin, 1988), the relevant experimental works are not even mentioned.

The few observations that have a direct bearing on the above question of recombination evolution caused by selection for fitness traits are presented in Table 1 . Most of these studies have shown unequivocally that adaptation to unfavourable conditions or selection for quantitative traits can result in appreciable changes in the recombination system. Thus, Flexon \& Rodell (1982) have shown that selection of Drosophila flies for resistance to DDT resulted in increased recombination after 300 days. Burt \& Bell (1987), in their attempts to discriminate between different models of recombination evolution, found a significantly higher number of chiasmata in males of domestic mammals compared with the respective wild species. Presumably, this difference reflects the reaction of the rec-systems of domesticated species to the long-term pressure of artificial selection. In a series of reproducible experiments, we have shown that adaptation of large cage populations of $D$. melanogaster to daily temperature fluctuations (with the amplitude increasing over generations) results in increased recombination (Zhuchenko et al., 1983, 1985; Gorodetsky et al., 1990; Korol et al., 1990).

The unidirectional mode of selection for fitness traits characterizes most of the studies presented in Table 1. An exception is the experiment with the mustard plant Brassica campestris (Harinarayama \& Murty, 1971) where increased chiasma frequency in pollen mother cells (PMC) was established after several cycles of selection for early and late flowering. The limitation of one-way selection schemes lies in the possible interpretation of recombination changes as trivial results caused by initial linkage disequilibria between selected genes and rec-modifiers. Here we report the effect of two-way selection for a behavioural trait in $D$. melanogaster on the recombination system. We present data on the effect of artificial selection for positive and negative geotaxis on crossing-over rates in all three large chromosomes. Geotaxis is expressed as a preferential orientation of flies (up or down) with respect to gravitation. This is one of the genetically best studied behavioural traits. The results indicate that, presumably, all of the three chromosomes are involved in the response to selection for geotaxis (Hirsch, 1967).

\section{Materials and methods}

The experiment was conducted on a large cage population established earlier by mixing 21 lines and maintained in the laboratory for more than 50 generations. Selection for geotaxis was carried out using a vertical 10-deadlock labyrinth (Hirsch, 1963). Flies were inserted into the labyrinth from the left and collected after their movement to the right according to their geotactic preferences. Negative geotaxis flies move to the upper vials of the labyrinth whereas positive ones tend to go to the lower vials. The time interval between the start of the test and extraction of the flies from the labyrinth (referred to as the estimation interval) was shortened step-wise during the course of selection. This was done because after a few generations of

Table 1 Effect of selection for fitness traits on recombination (a review)

\begin{tabular}{|c|c|c|c|}
\hline Organism & Selected trait & Effect on recombination & Reference \\
\hline $\begin{array}{l}\text { Mustard plant } \\
\text { B. campestris }\end{array}$ & $\begin{array}{l}\text { Early and late } \\
\text { flowering }\end{array}$ & $\begin{array}{l}\text { Increase in chiasma frequency } \\
\text { in PMC }\end{array}$ & Harinarayama \& Murty (1971) \\
\hline Mammals & $\begin{array}{l}\text { Domestication } \\
\text { complex }\end{array}$ & $\begin{array}{l}\text { Increased recombination } \\
\text { index in males }\end{array}$ & Burt \& Bell (1987) \\
\hline D. melanogaster & Resistance to DDT & $\begin{array}{l}\text { Increased } r f \text { in the large } \\
\text { autosomes }\end{array}$ & Flexon \& Rodell (1982) \\
\hline D. melanogaster & $\begin{array}{l}\text { Resistance to daily } \\
\text { temperature } \\
\text { fluctuations }\end{array}$ & $\begin{array}{l}\text { Marked increase of } r f \text { in large } \\
\text { autosomes and to a less extent } \\
\text { in the } X\end{array}$ & $\begin{array}{l}\text { Zhuchenko et al. }(1983,1985) \text {, } \\
\text { Gorodetsky et al. }(1990), \\
\text { Korol et al. }(1990)\end{array}$ \\
\hline D. melanogaster & $\begin{array}{l}\text { Positive and } \\
\text { negative geotaxis }\end{array}$ & $\begin{array}{l}\text { Increased } r f \text { in all three large } \\
\text { chromosomes }\end{array}$ & This study \\
\hline Yeast & $\begin{array}{l}\text { Resistance to } \\
\text { temporal variations } \\
\text { in nutrient medium }\end{array}$ & $\begin{array}{l}\text { Increased rate of sporulation } \\
\text { (sexual reproduction) }\end{array}$ & Wolf et al. $(1987)$ \\
\hline Mice & $\begin{array}{l}\text { High body weight } \\
\text { and high fertility }\end{array}$ & $\begin{array}{l}\text { Increased chiasma frequency } \\
\text { in the first case and reduced } \\
\text { in the second }\end{array}$ & Gorlov et al. (1992) \\
\hline
\end{tabular}


selection, the portion of flies reaching the highest scores (both in $\mathrm{geo}^{+}$and $\mathrm{geo}^{-}$) exceeded the chosen level of selection ( 10 per cent). Thus, to proceed with the same intensity of selection and the construction of the labyrinth, we had to shorten the estimation interval, thereby taking into account the fastest flies. According to reaction of experimental material, the estimation interval was $20 \mathrm{~min}$ in generations $1-5,5 \mathrm{~min}$ in generations 6-15, 3 min in generations $16-20$, and 1 $\mathrm{min}$ in generations $21-50$. Three hundred flies $(150$ males and 150 virgin females) were tested at each step of selection. Males and females were tested separately to exclude sexual behaviour components in the response. To establish each subsequent cycle of selection from the previous generation, 12 extreme females and 18 males were used for each direction of selection. Control flies were chosen randomly. In total, selection was practised during 50 generations.

The recombination frequency $(r f)$ was estimated for chromosomes 2, 3 and $\mathrm{X}$ in generations 36,40 and 44 , respectively. Females of the compared lines were crossed to marker stock males y cv ct v car, al b cn vg bw and ru h cu sre (markers on chromosomes X, 2 and 3 ). Then, two broods (of 3- and 2-day laying periods) were analysed with eight replicates of each testcross progeny of the hybrid females to marker males. The method of maximum likelihood was used to obtain the estimates of recombination rates. The significance of the deviations of selected lines from the control level was calculated using Student's $t$-test based on the arcsin transformation of $r f \mathrm{~s}$ for individual segments and the sum of untransformed $r$-values $(\Sigma)$ for the whole chromosomes.

\section{Results and discussion}

Significant response in geotactic behaviour was obtained in both directions of selection (Fig. 1). For generations presented in Fig. $1\left(F_{33}\right.$ and $\left.F_{49}\right)$, the deviations of $\mathrm{geO}^{-}$and $\mathrm{geO}^{+}$from the control level as well as the differences between the selected lines themselves were highly significant. Selection for opposite geotaxis directions brought about a dramatic increase in recombination frequency in different genomic regions (Table 2). The total increment in recombination for the genome portion considered is $78 \mathrm{cM}$ for $\mathrm{geo}^{+}$and $66 \mathrm{cM}$ for $\mathrm{geo}^{-}$. Selection for negative geotaxis did not result in $r f$ changes in chromosome 2 whereas selection in the opposite direction caused nearly a fourfold increase in $i f$ in the $b$-cn segment and a significant, albeit not as high, increase in the adjacent regions, $a l-b$ and $c n-v g$. A marked $r f$-response of the $b$ cn segment was also observed in our previous experiments with selection for Drosophila thermal adaptation (Zhuchenko et al., 1983, 1985; Gorodetsky et al., 1990; Korol et al., 1990).

How could these results be interpreted? We attribute the observed unidirectional change in $r f$ caused by two-way selection for geotaxis, to the advantage conferred by selection on recombinants. Moreover, the data as a whole indicate that changes in rec-loci are responsible for the effect. Some peculiarities of the experiment and the results seem to exclude several trivial alternative interpretations.

1 The stocks used in the founding population were tested for the presence of inversions and no inversions were detected. I. F. Zhimulev (Institute of Genetics and

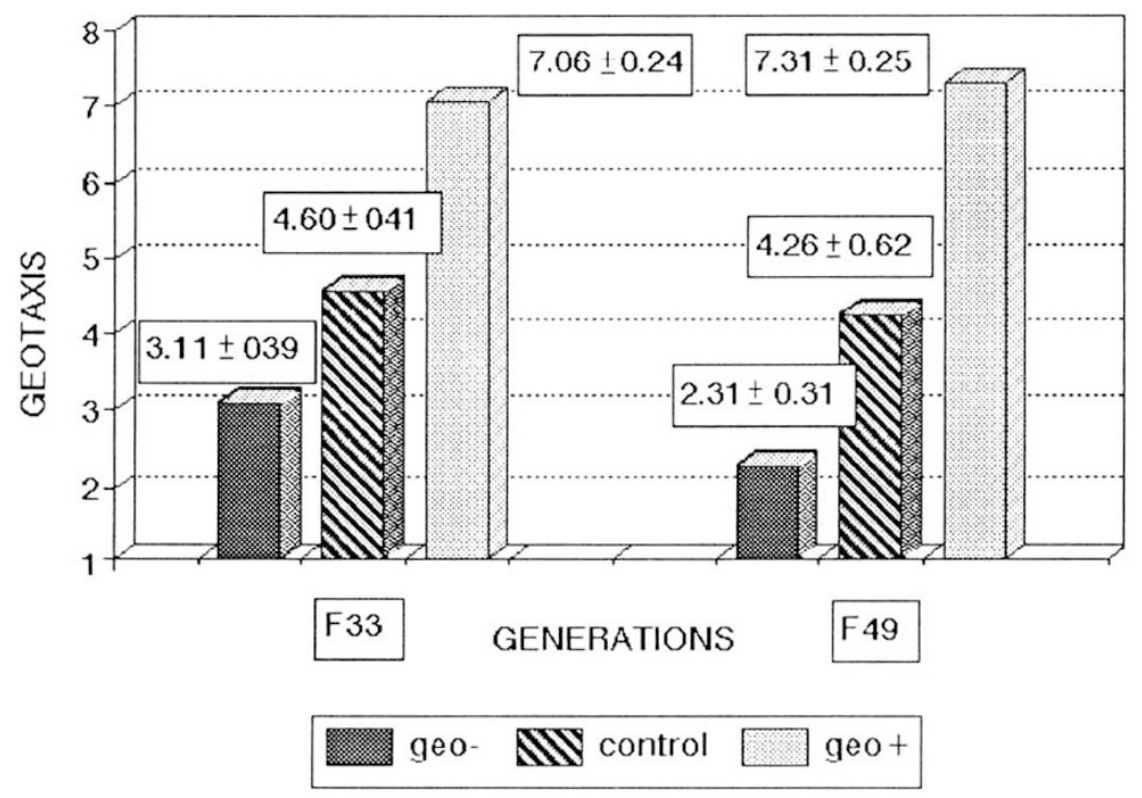

Fig. 1 Effectiveness of two-way selection for geotaxis in D. melanogaster. Geotaxis measured in conditional units connected with the labyrinth construction: the geotaxis axis is marked by consecutive numbers corresponding to the order of vials at the right side of the labyrinth, starting from the top. In the labyrinth number 1 corresponds to the negative extremes and number 10 to the positive ones. 
Table 2 Effect of two-way selection for geotaxis on recombination frequencies $(\%)$ in D. melanogaster

\begin{tabular}{|c|c|c|c|c|c|}
\hline Line & Segment & & & & \\
\hline \multicolumn{6}{|c|}{ Chromosome $X$} \\
\hline & $y-c v$ & $c v-c t$ & $c t-v$ & $v$-car & $\sum(y-c a r)$ \\
\hline $\mathrm{geo}^{+}$ & $37.95 \pm 1.12 \S$ & $22.31 \pm 0.99 \S$ & $19.98 \pm 0.85 \S$ & $30.07 \pm 0.72 \ddagger$ & $110.30 \pm 1.43 \S$ \\
\hline $\mathrm{geo}^{-}$ & $40.36 \pm 1.41 \S$ & $31.11 \pm 0.97 \S$ & $25.49 \pm 0.94 \S$ & $27.75 \pm 1.41 \dagger$ & $124.70 \pm 1.74 \S$ \\
\hline Control & $25.96 \pm 1.26$ & $13.16 \pm 0.70$ & $11.16 \pm 0.61$ & $22.36 \pm 1.65$ & $72.64 \pm 2.61$ \\
\hline \multicolumn{6}{|c|}{ Chromosome 2} \\
\hline & $a l-b$ & $b-c n$ & $c n-v g$ & $v g-b w$ & $\Sigma(a l-b w)$ \\
\hline $\mathrm{geo}^{+}$ & $44.45 \pm 1.89 \ddagger$ & $23.66 \pm 1.42 \S$ & $14.95 \pm 1.12 \S$ & $28.76 \pm 1.06$ & $111.82 \pm 2.62 \S$ \\
\hline $\mathrm{geO}^{-}$ & $33.32 \pm 1.83$ & $6.01 \pm 1.04$ & $9.68 \pm 0.96^{\circ}$ & $33.26 \pm 1.59$ & $82.28 \pm 2.62$ \\
\hline Control & $37.18 \pm 1.54$ & $6.27 \pm 0.94$ & $8.58 \pm 0.45$ & $31.50 \pm 0.58$ & $83.54 \pm 2.09$ \\
\hline \multicolumn{6}{|c|}{ Chromosome 3} \\
\hline & $r u-h$ & $h-c u$ & $c u-s r$ & $s r-e$ & $\Sigma(r u-e)$ \\
\hline $\mathrm{geO}^{+}$ & $14.44 \pm 0.36$ & $27.05 \pm 0.87 \S$ & $18.67 \pm 0.62 \S$ & $13.60 \pm 1.10$ & $73.76 \pm 1.41 \S$ \\
\hline $\mathrm{geo}^{-}$ & $13.73 \pm 0.64$ & $26.28 \pm 0.65 \S$ & $19.50 \pm 0.45 \S$ & $16.91 \pm 0.53 \S$ & $76.42 \pm 1.52 \S$ \\
\hline Control & $13.36 \pm 0.40$ & $18.85 \pm 0.41$ & $14.56 \pm 0.60$ & $14.02 \pm 0.28$ & $60.79 \pm 1.07$ \\
\hline
\end{tabular}

$\dagger, \ddagger$ and $\S$, deviation from control significant at $P<5,1$ and $0.1 \%$.

Cytology, Novosibirsk) kindly helped in this test. The hypothesis of homozygotization of inversions (even if caused by selection) cannot explain the exclusive upwards change in $r f$. Thus, normal gene orders, colinear to those of the standard marker stocks, became fixed.

2 The fact that $r f$ has increased under selection in both directions means that possible linkage disequilibria between selected genes affecting geotaxis and rec-loci is rather improbable.

3 Known effects of recombination dependence on inbreeding are irrelevant to our experimental design because the consequences of selection have been estimated using hybrid females resulting from crosses of females from three compared lines to tester males marked for the chromosome of interest.

4 To exclude possible effects of $P$-element transpositions on recombination, the founding population was tested for $P$-potential and $P$-susceptibility (based on ovarian sterility measured in corresponding crosses) and clearly classified as $M$. Later, to obtain heterozygote flies for $r f$ estimation, the control and selected strains were used as female parents in crosses to marker strains. This prevents the influence of hybrid dysgenesis on recombination if even some of the compared strains were polymorphic for $P$.

5 An important question regarding these data is the possibility of random effects caused by the low number of selected progeny and the absence of parallel replicates. The main arguments against such an interpretation and in favour of the one presented here are: (i) the unidirectional mode of changes in $r f$ in both $\mathrm{geo}^{+}$and $\mathrm{geo}^{-}$(which are more than simply two independent replications); (ii) reaction of different genome regions in the same direction; (iii) very high rates of $r$-reaction are not very common in experiments with direct selection for recombination. In fact, the observed differences between opposite selection lines rarely exceed the two or threefold level (Chinnici, 1971; Kidwell, 1972; Dewees, 1975; Charlesworth \& Charlesworth, 1985; but see Turner, 1979); and (iv) good reproducibility of the effects between replications (eight replications for each line tested for each of the three chromosomes).

The total increment in recombination across the studied portion of the genome was more than 66 per cent in the $\mathrm{geo}^{-}$line and 78 per cent in $\mathrm{geo}^{+}$. All of the three large chromosomes showed significant change in $\mathrm{geO}^{+}$whereas only two in $\mathrm{geo}^{-}$(chromosomes X and 3 ). This difference in the $r f$-reaction of the opposite selected lines needs some comments. Possibly, it could be explained by an assumption that effective minus alleles of the chromosome 2 loci controlling geotaxis were not polymorphic in the start population. We should recall here that there is a characteristic tendency for negative geotaxis in D. melanogaster. Therefore, the above assumption of fixation of $\mathrm{geo}^{-}$ alleles seems to be reasonable. However, the observed pattern of recombination changes across the genome does not necessarily reflect directly the distribution of geotaxis or rec-loci. Indeed, in experiments with direct selection for recombination, it has been shown that the response to selection for one specific chromosome region can result in a spectrum of changes in recom- 
bination in many genomic regions with different chromosomes being involved in this changed control of recombination (Chinnici, 1971; Kidwell, 1972; Charlesworth \& Charlesworth, 1985).

Based on our data and other evidence (Table 1), it can be generalized that directional selection for any trait for many generations can play an important role in rec-system evolution. Of course, the selection regime is of prime importance in such evolution, particularly with respect to its direction and rate (Maynard Smith, 1988; Bergman \& Feldman, 1990; Korol et al., 1990; B. Charlesworth, unpublished data). Presumably, the effect cannot continue indefinitely because genetic variability will be exhausted for the selected trait. In general, and in contrast to the occasionally voiced pessimism, it seems reasonable to assume that direct large-scale modelling on convenient experimental organisms, together with observations in nature, could help to further significant progress in our understanding of the forces of recombination evolution.

\section{Acknowledgements}

The work was partly supported by grants from the Israeli Ministry of Science (No. 3675-1-91) and Wolfson Family Charitable Trust. We wish to thank Professor E. Nevo, Dr A. Beiles, Dr L. Blaustein and an unknown referee for helpful discussions and comments on the manuscript, Dr Natalia M. Vereshchagina for the material used as the founder population and Professor I. F. Zhimulev for his help in testing the initial lines for the presence of inversions.

\section{References}

ALLARD, R. W. 1963. Evidence for genetic restriction of recombination in the lima bean. Genetics, 48, 1389-1395.

BELL, G. AND MAYNARD SMITH, J. 1987. Short-term selection for recombination among mutually antagonistic species. Nature, 328, 66-68.

BERGMAN, A. AND FELDMAN, M. w. 1990. More on selection for and against recombination. Theor. Popul. Biol., 38, 68-92.

BURT, A. AND BELL, G. 1987. Mammalian chiasma frequencies as a test of two theories of recombination. Nature, $\mathbf{3 2 6}$, $803-805$.

CHARLESWORTH, B. 1976. Recombination modification in a fluctuating environment. Genetics, 83, 181-195.

CHARLESWORTH, B. 1990. Mutation-selection balance and the evolutionary advantage of sex and recombination. Genet. Res., 55, 199-221.

CHARLESWORTH, B. AND CHARLESWORTH, D. 1985. Genetic variation in recombination in Drosophila. II. Genetic analysis of a high recombination stock. Heredity, 54, 85-98.

CHINNICI, J. P. 1971. Modification of recombination frequency in Drosophila. II. The polygene control of crossing over. Genetics, 69, 85-96.
DEWEES, A. A. 1975. Genetic modification of recombination rate in Tribolium castaneum. Genetics, 81, 537-552.

FELSENSTEIN, J. AND YOKOYAMA, S. 1976. The evolutionary advantage of recombination. Individual selection for recombination. Genetics, 83, 845-859.

FLEXON, P. B. AND RODELL, C. F. 1982. Genetic recombination and directional selection for DDT resistance in Drosophila melanogaster. Nature, 298, 672-675.

GORLOV, I., SCHULER, L., BUNGER, L. AND BORODIN, P. 1992. Chiasma frequency in strains of mice selected for litter size and for high body weight. Theor. Appl. Genet., 84, 640-642.

GORODETSKY, V. P., ZHUCHENKO, A. A. AND KOROL, A. B. 1990. Efficiency of feedback selection for recombination in Drosophila. Genetika (USSR), 26, 1942-1952.

HAMiLTON, w. D. 1980. Sex versus non-sex versus parasite. Oikos, 35, 282-290.

HARINARAYAMA, G. AND MURTY, B. R. 1971. Cytological regulation of recombination in Pennisetum and Brassica. Cytologia, 36, 345-348.

HIRSCH, J. 1963. Behavior genetics and individuality understood. Science, 142, 1436-1442.

HIRSCH, J. (ed.) 1967. Behavior-Genetic Analysis. McGrawHill, New York.

KIDWELL, M. G. 1972. Genetic change of recombination value in Drosophila melanogaster. 1. Artificial selection for high and low recombination and some properties of recombination modifying genes. Genetics, 70, 419-432.

KONDRASHOV, A. S. 1988. Deleterious mutations and the evolution of sexual reproduction. Nature, 336, 435-440.

KOROL, A., PREYGEL, I. AND PREYGEL, S. 1990. Variability of Crossing-over in Higher Organisms. Shtiintsa, Kishinev (in Russian). (English version in press, Chapman \& Hall.)

LANDNER, L. 1971. Genetic control of recombination in Neurospora crassa: correlated regulation in unlinked chromosome intervals. Heredity, 27, 385-392.

MAYNARD SMITH, J. 1980. Selection for recombination in a polygenic model. Genet. Res., 35, 269-277.

MAYNARD SMITH, J. 1988. Selection for recombination in a polygenic model: the mechanism. Genet. Res., 51, 59-63.

MiCHOD, R. E. AND LEVIN, B. R. (eds.) 1988. The Evolution of Sex. An Examination of Current Ideas. Sinauer, Sunderland.

SHAW, D. D. 1972. Genetic and environmental components of chiasma control. II. The response to selection in Schistocerca. Chromosoma, 37, 297-308.

stearns, s. G. (ed.) 1987. The Evolution of Sex and its Consequences. Birkhauser, Basel.

TURNER, J. R. G. 1979. Genetic control of recombination in the silkworm. Heredity, 43, 273-293.

WOLF, H. G., WOHRMANN, K. AND TOMiUK, J. 1987. Experimental evidence for the adaptive value of sexual reproduction. Genetica, 72, 151-159.

ZHUCHENKO, A. A., KOROL, A. B., KOVTYUKH, L. P. AND TABAK, E. P. 1983. Increased crossing-over frequency in a population experiencing selection for a resistance to temperature fluctuations. Doklady Acad. Nauk USSR, 273, 721-725.

ZHUCHENKO, A. A., KOROL, A. B. AND KOVTYUKH, L. P. 1985. Change of crossing-over frequency in Drosophila during selection for resistance to temperature fluctuations. Genetica, 67, 73-78. 